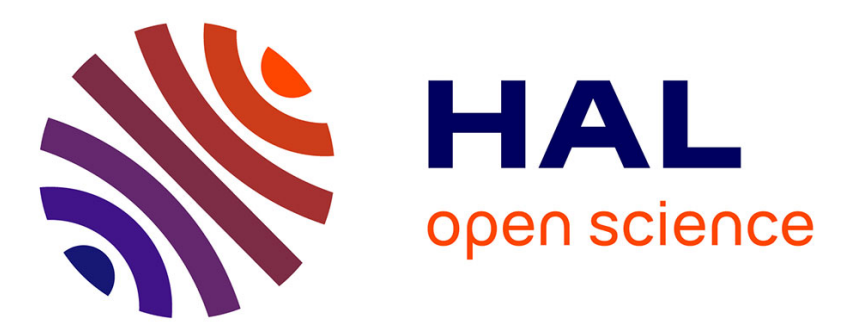

\title{
Energy efficiency as an example of cross-discipline collaboration in chemical engineering
}

\author{
Jean-Charles de Hemptinne, Jean-Henry Ferrasse, A. Gorak, Signe Kjelstrup, \\ F. Maréchal, Olivier Baudouin, R. Gani
}

\section{- To cite this version:}

Jean-Charles de Hemptinne, Jean-Henry Ferrasse, A. Gorak, Signe Kjelstrup, F. Maréchal, et al.. Energy efficiency as an example of cross-discipline collaboration in chemical engineering. Chemical Engineering Research and Design, 2017, 119, pp. 183-187. 10.1016/j.cherd.2017.01.020 . hal-01519871

\section{HAL Id: hal-01519871 \\ https://hal.science/hal-01519871}

Submitted on 19 May 2017

HAL is a multi-disciplinary open access archive for the deposit and dissemination of scientific research documents, whether they are published or not. The documents may come from teaching and research institutions in France or abroad, or from public or private research centers.
L'archive ouverte pluridisciplinaire HAL, est destinée au dépôt et à la diffusion de documents scientifiques de niveau recherche, publiés ou non, émanant des établissements d'enseignement et de recherche français ou étrangers, des laboratoires publics ou privés. 


\title{
Energy efficiency as an example of cross-discipline collaboration in Chemical Engineering
}

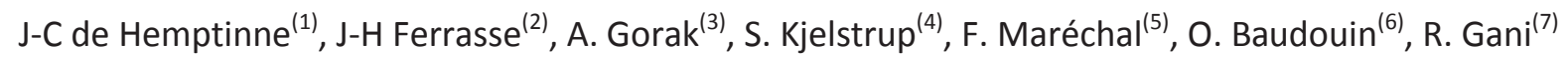

(1) IFP Energies Nouvelles, 1 et 4 Avenue de Bois-Préau, 92852 Rueil-Malmaison Cedex, France

(2) Aix-Marseille Univ, CNRS, Centrale Marseille, M2P2, Marseille, France

(3) TU Dortmund University, Laboratory of Fluid Separations, 44221 Dortmund, Germany

(4) Norwegian University of Science and Technology, Department of Chemistry, NO 7491 Trondheim, Norway

(5) Ecole Polytechnique Fédérale de Lausanne, SCI-STI-FM, ME A2 434, Station 9, CH-1015 Lausanne, Switzerland

(6) ProSim SA, Immeuble Stratege A, 51 rue Ampere, F-31670 Labege, France

(7) Department of Chemical and Biochemical Engineering, Technical University of Denmark, DK2800 Lyngby, Denmark

Keywords:

Thermodynamics; Chemical engineering; Energy efficiency; interdisciplinarity; exergy

\begin{abstract}
This paper summarizes the round-table discussion that was held during the European Congress of Chemical Engineering (ECCE) in Nice, France, in October 2015 on this topic. The panellists come from different fields of Chemical Engineering and have thus brought in different perspectives. The objective was to determine paths for developing innovative approaches in view of process optimization.
\end{abstract}

The terminology is a first obstacle that was clarified. Energy efficiency can be envisaged either by optimizing thermodynamic functions (entropy or exergy), more pragmatically by selecting the adequate unit operation or in a very general vision by considering all decision variables (i.e. including economic and political) that may have an impact on the final service provided to society.

The second issue relates to improving collaboration among various actors. These may be defined in terms of type of responsibility (industrials, mostly market-driven, or academic), or in terms of discipline. The role of professional societies as the European Federation for Chemical Engineers (EFCE) is stressed as a promotor of collaboration between disciplines.

Finally, once willingness for collaboration is identified, the final question is how it can lead to true innovation. The largest innovation potential is often found at the interface between fields. Yet, it often requires both an effort to explain the mutual challenges in a didactic manner, and the development of tools that make it possible to each partner to be efficient in his own field while being aware of the global goal and of the constraints of the others. 


\section{Introduction}

Chemical Engineer is a profession where a global systems approach is needed in addition to a detailed understanding of the underlying chemistry and physics. To integrate the two scales requires both types of expertise and a common language for communication between experts of different fields. Yet, we too often observe that the same words are used with different meanings, depending of the community we are in. In order to improve cross-competence communication, the European Federation of Chemical Engineers (EFCE) Working Party on Thermodynamics and Transport Properties and the managerial team for the topic on "Energy: resources, conservation and management" organized a round-table discussion during the $10^{\text {th }}$ European Congress of Chemical Engineering (ECCE10) in Nice (September 26-October $1^{\text {st }}$ 2015). The title of the discussion was "Thermodynamic analysis methods for Process Energy Systems Engineering".

As in the previous editions of the "Industrial Use of Thermodynamics" (IUT) Symposium 1,2, the content of the discussion and the main conclusions are presented here. Seven panellists were asked an opinion and to deepen the answer in the discussion. A summary with details of this is provided.

The discussion was structured around three questions:

- Elaborate on the different vocabulary leading to possible misunderstandings

- Identify obstacles to work across disciplines

- Point to potential collaborations

\section{A. What does "thermodynamic analysis" or "energy optimization" mean in my context?}

\section{Thermodynamic point of view:}

An energy-optimal process aims at minimizing entropy production subject to constraints (e.g. inlet/outlet conditions). Using distillation as an example of a process unit, this optimization means finding the exact temperature and the corresponding amount of heat that needs to be delivered/taken away at any position along the column. Control theory provides a robust tool to find the optimal state of operation of a unit ${ }^{3,4}$. The entropy production can be expressed in terms of rates and driving forces, as in non-equilibrium thermodynamics, or from the entropy or exergy balance. The entropy production times the temperature of the surroundings is the destructed exergy. For systems consisting of several units, exergy analysis is useful.

The example of distillation is of course excellent, with insight that can be transferred to other unit operations. For example, optimization of dryers, a huge energy consumer, would require further understanding of transient operations and thermodynamics of material. Non-equilibrium thermodynamics could be applied, but need further development to be included in regular engineering. 
Energy optimization can be viewed at two levels: at the unit operation level or the level of the whole process.

At the level of the unit operation, the task is to design the separation equipment in the right operating window (e.g. the optimal reflux ratio or gas to liquid ratio). It also means to look for processes which can replace traditional separation through new ones, e.g. distillation through organic solvent nanofiltration or absorption through membrane contactors ${ }^{5,6}$. We can also reduce energy consumption through integration of several unit operations within one shell (e.g. reactive distillation or divided wall column). The algorithmic optimization of sequences of separation units leads also to substantial energy savings.

Looking at the global process, tools and methodologies are used to minimize energy consumption. Pinch analysis is a well-known method for heat process integration, used for decades, and very powerful for optimization of the whole process efficiency ${ }^{7-9}$. It does not consider the inside of the equipment. A less familiar concept to chemical engineers, with more thermodynamic insights, is the "exergetic analysis", which exploits the concept of energy quality to quantify the portion of energy that can be practically recovered ${ }^{10}$. These two methods are complementary: the exergy method provides improvements when the Pinch method may fail, in particular for processes under pressure, or for separation processes that require more than a single stage, i.e., a cascading separation system.

\section{Systems point of view}

Thermodynamic analysis provides answers to questions of feasibility of operation-task, for example, reaction and/or separation ${ }^{11}$. An operation-task judged to be thermodynamically feasible, does not mean that it necessarily operates optimally. For this, a set of criteria need be established. Thermodynamic analysis helps to define some of these criteria. They are, however, not exclusive or sufficient. They could be termed as necessary and useful. Energy optimization should try to optimize (minimize) the energy consumption of the process. How this is achieved, can vary from case to case, and how the solution is found depends on how the energy demands/needs are estimated. Note also that there is a difference between energy optimization achieved in a process and energy optimized process design solution. Although, thermodynamics (thermodynamic analysis) can point towards some solution, it needs to be verified, by experiments and/or rigorous models.

\section{As a conclusion:}

The discussion clearly points to the multiscale dimension of the problem. It is an advantage to understand the entropy production on the molecular scale, in order to fully benefit from multiobjective systems optimization. Classical tools, as pinch analysis ${ }^{12}$ remain of interest, but can preferably be complemented with exergy analysis ${ }^{10,13}$. Adequate modelling of the phenomena requires the selection of the adequate physical model and physical insight at the right scale while considering at the same time the level of uncertainties of the definition of the boundary conditions.

The overall analysis should first seek non-trade-off solutions. If not found, a multi-objective optimization should be set up that requires a clear definition of the constraints and of the system boundaries and seeks to generate Pareto sets of solutions that will be used for decision support. It depends largely on the domain (the unit operation, plant or global society)- 
$\rightarrow$ Among the objective functions, one must include an entropy based criteria such as exergy but also economic considerations, and also others as environmental impact, waste production, toxicity , ... adopting therefore a life cycle assessment (LCA) approach.

$\rightarrow$ Among the constraints, the technical feasibility of the solutions will limit the search space, therefore optimization requires care in the definition, the understanding and the modelling of constraints and bounds that could lead to further technological development challenges.

$\rightarrow$ The results depend on the system boundaries: whether the analysis is performed on the scale of the plant, the region, country or on the global scale. It is important to always leave the door open to system limit expansion especially in highly grid integrated countries.

Improving energy efficiency clearly requires the input of different fields of expertise. Collaborative efforts are needed.

\section{B. What are the obstacles inhibiting collaborative efforts for innovation?}

\section{An issue of trust?}

In the situation that we all want to foster innovation, one obstacle seems to be a sceptical attitude that exists between physicists and engineers, scientists or industrialists in the field of thermodynamics. The lack of innovation can be described by an "activation energy" for learning of the vocabulary and way of thinking in a new discipline, coming from fear to fail, or from not having enough merits in being intra-disciplinary and interdisciplinary. Altogether, the existence of well established "traditional" processes can be a huge barrier to make a new process SIGNIFICANTLY better or cheaper, and benefits are sometimes "fuzzy" ${ }^{14}$.

\section{$\underline{\text { An issue of vocabulary? }}$}

Different disciplines use different language to identify the same actions that have the same goals. The discussion in part A above illustrates this quite well: the concept of "exergy analysis" is often restricted to entropy analysis for energy specialist while it may include economic concepts from the systems point of view. Examples of communities that use similar terminology with different meaning are the thermal engineering community, the process engineering and the life cycle analysis communities. This may lead to re-invent concepts without true innovation.

Another important aspect is the understanding of the priorities and the key concerns of the different disciplines that can bias the analysis : what is important for one community is "just" a mean for the others. As an example, "new" concepts, such as exergy or advanced equations of state, can be considered by industrial partners as only academic tools which are not well designed for their everyday need.

To be efficient, collaborative efforts for innovation should include collaborations between industrial and academic partners. Unfortunately, it is often hampered by confidentiality of industrial data 
(industrial partners can't broadcast in-house information and academic partners need to publish their works).

\section{An issue of methodology?}

Implementation of a new or novel or innovative solution (design) need much more than a thermodynamic analysis. A cost analysis and these days, also a sustainability analysis (including Life Cycle Analysis), would make it easier to decide if the investment should be made ${ }^{15}$.

The lack of inter-disciplinarity consciousness and methodology is therefore a key issue in the framework of an inhibited collaboration. One obstacle is the lack of systemic understanding of the innovation process that prevents researchers to understand their interactions with the other fields and researchers. This is obviously surprising in the field of process and energy systems engineering.

\section{Conclusion:}

Collaborative efforts are always there when all partners can get mutual benefits from such collaboration and have a mutual understanding of the benefit of the others. An example of such an effort for working towards innovation is the SPIRE European initiative. It aims at ensuring the development of enabling technologies for improving the use of resources. Innovation is then achieved when a global vision of the system is achieved.

Innovation can be viewed, at least from two different points of view: (1) to be able to put the correct idea in front of a well-defined need or (2) to be able to bring together people with different visions.

The well-defined need is often considered very differently by different actors. Without being restrictive, it can be stated that academic work aims at proposing new ideas, but that the motivation is often related to the "beauty" of the solution proposed. This is in opposition to the industrial approach who aim at solving problems driven by economic reasons: the fear is the size of the investment compared to limited benefits. The objectives are different and limit the level of understanding of the other's standpoint. A risk must be taken and shared by all parties, which requires understanding of each other's position.

Education is therefore key: one may not be specialist in all fields, but the adequate training is needed to be able to understand the concepts and the vocabulary of the different disciplines. Examples of cross-disciplinary projects for students are therefore crucial.

Finally, it the availability of adequate decision support tools (including simulation, optimization, data bases) is crucial so that non-experts can work with the concepts.

\section{How can improving knowledge in my field help improving the other fields?}

This question relates to the connections between inter-disciplinary and intra-disciplinary research. Chemical Engineering is by essence a discipline that requires many different scientific fields to collaborate, but it may happen that barriers are raised such that connections become difficult. 
Thermodynamic analysis is to be applied in all sectors and well beyond chemical engineering (mechanical, car manufacturing, even finance!)

\section{Some success stories:}

Software vendors propose tools that make it easier to communicate across disciplines: tools must be such that they can be used for different types of applications (examples are simple Excel Sheets and Process Simulation Software) ${ }^{16,17}$. The use of common scales and measures should be encouraged ${ }^{18}$.

A Swiss example is important ${ }^{19}$. Here (Canton of Geneva) the concept of exergy was introduced in legal texts: any new project must demonstrate its effectiveness from an exergy point of view (in additional to the classical economic analysis). This was achieved by educating the authorities and decision-makers.

\section{$\underline{\text { Look at interfaces }}$}

It is expected ${ }^{20}$ that when a field is mature, there is a natural trend of researchers to look for emerging areas, which usually lie at the interface between fields or disciplines. After this interface has been identified, new applications emerge, which require improvement in one's own field. Because of these interactions we should look for interfaces and allow researchers to look for synergies between fields which do not seem to have any common window.

\section{Need for multiscale tools:}

As an example, one could take better advantage of entropy production minimization procedures ${ }^{21}$. It is useful to understand the explicit expression, the molecular origin and the various functional dependencies of the entropy production. This is provided by the field of non-equilibrium thermodynamics. However, there is presently no systematic teaching of this field in engineering schools or science programs of this theory. To mend this may improve the basic description of many applications in many fields. A few universities in US and Europe have started this endeavor.

Software vendors have to be the link between industrial and academic partners, in order to create a virtuous triangle ${ }^{2}$ between industrials end-users, academic researchers and software vendors. The situation is that

$\rightarrow$ Process design and optimization, as well as exergy analysis, need precise and reliable thermodynamic models. Software vendors have to integrate more physical based models.

$\rightarrow$ "New concepts/new technologies" models, such as DWC (Dividing Wall Columns) or HIDiC (Heat Integrated Distillation Columns), should be available in process simulation software in order to be easily considered as alternatives during the conceptual design phase of a process. Such models should consider not only simulation but all the necessary information to analyse their integration, like heat integration, life cycle assessment, sizing procedure and cost estimation ${ }^{22}$.

$\rightarrow$ Process simulation software should provide easy-to-use tools for well-known methodology such as pinch analysis but also more advanced concept such as exergy analysis.

\section{Conclusion}


Promoting further research in one's own field should never come at the expense of a healthy curiosity across disciplines. This forth and back movement may result in new visions and therefore lead to innovations.

\section{Conclusions}

As a summary of the discussion, a number of messages seem to come up as important:

$\rightarrow$ Multiscale tool development

It is essential that tools be available at various levels of applications:

- At the molecular level: understand the role of energy and mechanisms of entropy creation. This can be done for example using molecular simulation tools or from Onsager flux-forces relations.

- At the macroscopic level, the use of the calculation of exergy or entropy creation should be made available in all process simulators and the use of the exergy concepts has to be part of the engineering curriculum.

- Other tools for helping Decision makers at the level of a region, a country, or at the global level (e.g. LCA or process integration), should integrate thermodynamic based concepts to offer a better understanding the role of the energy.

$\rightarrow$ Communication across disciplines

We are used to educate students within our own discipline, which makes it easy to go into the details of the concepts. Yet, it is clearly important to construct clear messages that can be understood by non-specialists, either in the engineering community, or even beyond, by the general public.

\section{References}

(1) Economou, I. G.; Hemptinne, J.-C. de; Dohrn, R.; Hendriks, E.; Keskinen, K.; Baudouin, O. Industrial use of thermodynamics workshop: Round table discussion on 8 July 2014. Advances in Thermodynamics for Chemical Process and Product Design [Online] 2014, 92 (12), 2795-2796. http:// www.sciencedirect.com/science/article/pii/S0263876214004754.

(2) Kontogeorgis, G. M.; Jaubert, J.-N.; Hemptinne, J.-C. de. Éditorial. Oil Gas Sci. Technol. - Rev. IFP Energies nouvelles [Online] 2013, 68 (2), 187-215. http://dx.doi.org/10.2516/ogst/2013|20.

(3) Kjelstrup, S.; Bedeaux, Dick, Johanssen, D.; Gross, J. Non-equilibrium thermodynamics for engineers; World Scientific: New Jersey [u.a.], 2010.

(4) Sankaranarayanan, K.; Swaan Arons, Jakob de; Kooi, Hedzer van der. Efficiency and sustainability in the energy and chemical industries: Scientific principles and case studies, 2 nd ed.; Green chemistry and chemical engineering; CRC Press/Taylor \& Francis: Boca Raton, FL, 2010.

(5) Lutze, P.; Gorak, A. Reactive and membrane-assisted distillation: Recent developments and perspective. The 60th Anniversary of the European Federation of Chemical Engineering (EFCE) [Online] 2013, 91 (10), 1978-1997. http://www.sciencedirect.com/science/article/pii/ S0263876213002888.

(6) Skiborowski, M.; Harwardt, A.; Marquardt, W. Conceptual Design of Distillation-Based Hybrid Separation Processes. Annu Review Chem Biomol Eng, 2013, 45-68.

(7) Grossmann, I. Enterprise-wide optimization: A new frontier in process systems engineering. AIChE J. [Online], 2005, 1846-1857. http://dx.doi.org/10.1002/aic.10617. 
(8) Grossmann, I. E. Advances in mathematical programming models for enterprise-wide optimization. FOCAPO 2012 [Online] 2012, 47, 2-18. http://www.sciencedirect.com/science/article/ pii/S0098135412002220.

(9) Chen, Y.; Eslick, J. C.; Grossmann, I. E.; Miller, D. C. Simultaneous process optimization and heat integration based on rigorous process simulations. Special Issue: Selected papers from the 8th International Symposium on the Foundations of Computer-Aided Process Design (FOCAPD 2014), July 13-17, 2014, Cle Elum, Washington, USA, Computers and Chemical Engineering [Online] 2015, 81, 180-199. http://www.sciencedirect.com/science/article/pii/S0098135415001349.

(10) Kotas, T.J.: The exergy method of thermal plant analysis; Kotas, V. T., Ed.; Butterworth Publishers, 1985.

(11) Jaksland, C. A.; Gani, R.; Lien, K. M. Separation process design and synthesis based on thermodynamic insights. Chem.Eng.Sci. [Online] 1995, 50 (3), 511-530. http:// www.sciencedirect.com/science/article/pii/000925099400216E.

(12) Linnhoff, B. Thermodynamic Analysis in the Design of Process Networks, Leeds University, Leeds, UK, 1979.

(13) Szargut, J. Exergy method: Technical and ecological applications; International series on developments in heat transfer; WIT: Southampton, 2005.

(14) Runge, W. Innovation, research and technology intelligence in the chemical industry: Integrated business, technical and systems approaches; Fraunhofer-IRB-Verl: Stuttgart, 2006.

(15) Babi, D. K.; Holtbruegge, J.; Lutze, P.; Gorak, A.; Woodley, J. M.; Gani, R. Sustainable process synthesis-intensification. Special Issue: Selected papers from the 8th International Symposium on the Foundations of Computer-Aided Process Design (FOCAPD 2014), July 13-17, 2014, Cle Elum, Washington, USA, , Computers and Chemical Engineering [Online] 2015, 81, 218-244. http:// www.sciencedirect.com/science/article/pii/S0098135415001313.

(16) Ghannadzadeh, A.; Thery-Hetreux, R.; Baudouin, O.; Baudet, P.; Floquet, P.; Joulia, X. General methodology for exergy balance in ProSimPlus ${ }^{\circledR}$ process simulator. Integration and Energy System Engineering, European Symposium on Computer-Aided Process Engineering 2011 [Online] 2012, 44 (1), 38-59. http://www.sciencedirect.com/science/article/pii/S0360544212001120.

(17) Gourmelon, S.; Thery-Hetreux, R.; Floquet, P.; Baudouin, O.; Baudet, P.; Campagnolo, L. Exergy analysis in ProSimPlus ${ }^{\circledR}$ simulation software: A focus on exergy efficiency evaluation. Computers \& Chemical Engineering [Online] 2015, 79, 91-112. http://www.sciencedirect.com/science/article/pii/ S0098135415000599.

(18) Science Europe. A Common Scale for Our Common Future: Exergy, a Thermodynamic Metric for Energy: Recommendations from the Science Europe Physical, Chemical and Mathematical Sciences Committee, 2015.

(19) Favrat, D., Maréchal, F., \& Epelly, O. (2008). The challenge of introducing an exergy indicator in a local law on energy. Energy, 33(2), 130-136.

(20) Gorak, A.; Stankiewicz, A. Intensified Reaction and Separation Systems. Annu Review Chem Biomol Eng, 2011, 431-451.

(21) Johannessen, E.; Kjelstrup, S. A highway in state space for reactors with minimum entropy production. Chem.Eng.Sci. [Online] 2005, 60 (12), 3347-3361. http://www.sciencedirect.com/ science/article/pii/S0009250905000862.

(22) Gerber, L., Gassner, M., \& Maréchal, F. (2011). Systematic integration of LCA in process systems design: application to combined fuel and electricity production from lignocellulosic biomass.

Computers \& Chemical Engineering, 35(7), 1265-1280. 